\title{
Guerra do Pacífico: discursos nacionais em foco
}

\section{Rafael Pessolato Marchesin*}

HOSIASSON, Laura Janina. Nação e Imaginação na Guerra do Pacífico. São Paulo: Editora da Universidade de São Paulo, 2011. 176 p.

As relações existentes entre o contexto de guerra e a produção de discursos nacionalistas inspiram as reflexões desenvolvidas no livro Nação e Imaginação na Guerra do Pacífico, de Laura Janina Hosiasson. A autora, que na atualidade está vinculada ao Departamento de Letras Modernas da Universidade de São Paulo (USP), tem se dedicado especialmente ao estudo da literatura hispano-americana. A sua publicação atual, resultante da pesquisa de doutoramento, reflete essa linha de investigação. $\mathrm{O}$ trabalho de Laura Hosiasson debruça-se sobre as narrativas nacionalistas produzidas a partir da experiência da Guerra do Pacífico. Este foi um conflito travado no hemisfério sul-americano entre os anos de 1879 e 1883, em que o Chile enfrentou uma aliança militar composta pela Bolívia e pelo Peru. Como ressalta a autora já na "Nota Introdutória", as origens do conflito estavam diretamente associadas à disputa de territórios ricos em recursos naturais, notadamente o guano (dejetos de aves marinhas) e posteriormente o salitre. Estas substâncias se configuraram em mercadorias que representavam uma importante possibilidade de inserção de Estados recémformados -como eram os países latino-americanos- no mercado mundial. Da associação de causas nacionais a interesses econômicos internacionais (inclusive europeus) resultaram os mortíferos confrontos armados. Foi após esses enfrentamentos que se deu uma nova conformação de fronteiras, conformação esta que passou a privar os bolivianos de acesso ao mar, gerando profundos ressentimentos e divergências diplomáticas que se estendem até a atualidade. Pois partindo deste contexto histórico intenso e dramático, Laura Janina Hosiasson passa a desenvolver suas reflexões, trabalhando com a hipótese central de que "a literatura gerada pela Guerra do Pacífico está imbuída do objetivo de consolidar o conceito de nação nos três países envolvidos no conflito, sejam eles vitoriosos ou derrotados" (p. 32). Assim, elaborando suas

\footnotetext{
* Mestre em História Social pela Universidade de São Paulo. E-mail: rafael.marchesin@ usp.br.

Revista Eletrônica da ANPHLAC, n.14, p. 325-329, jan./jun. 2013. http://revista.anphlac.org.br/index.php/revista
} 
análises a partir de obras consideradas literariamente secundárias ou mesmo menores, a autora estrutura o seu trabalho em quatro capítulos.

Com o título "A viagem para a guerra ou a construção do patriota", o primeiro capítulo se desenvolve fundamentalmente em função da análise de dois livros. $\mathrm{O}$ primeiro deles é Crónica de un soldado de la Guerra del Pacífico, redigido em 1881 pelo combatente chileno Hipólito Gutiérrez, que desenvolve sua narrativa a partir da saída de sua cidade natal em setembro de 1879, passando pelos confrontos e encerrando o relato com o seu regresso ao porto chileno de Valparaíso em março de 1881. E a outra obra analisada é Recuerdos de la Campaña de 1879, do soldado boliviano Miguel Birbuet España, escrito em 1879 (ano em que a Bolívia começa a se afastar da guerra), refletindo a atmosfera soturna que acompanhava as tropas bolivianas. Estas duas narrativas, que em essência constituem relatos de viagem com ênfase nos deslocamentos, são submetidas a uma interessante análise de Laura Janina Hosiasson, que passa a apontar em tais obras a existência de uma forte carga simbólica nacionalista. As movimentações das tropas são vistas como uma espécie de rito patriótico, como uma espécie de imersão na vida nacional capaz de reforçar, reconfigurar -ou mesmo forjaro sentimento de identidade nacional nos narradores e nos leitores, ainda que este processo se dê de maneira contraditória, pois, ao sair de sua comunidade simbólica local, o combatente (ou o leitor) entra em contato com realidades sociais e geográficas novas e mais amplas que eram até pouco desconhecidas, mas que passarão a ser incorporadas no imaginário em função do sentimento de pertencimento nacional. É também graças a este deslocamento militar provocado pela guerra que são estabelecidas as alteridades, pois, na América hispânica, onde língua e composição étnica não se prestam para demarcar fronteiras e territórios, a luta colocará em campos opostos os membros da comunidade nacional e os excluídos dela, os inimigos a serem combatidos. A viagem é apresentada, assim, como uma espécie de processo pedagógico que ensina aos homens as paisagens e belezas da pátria ao mesmo tempo em que indica os inimigos que a ameaçam. Já neste capítulo inicial fica exposta boa parte das referências teóricoconceituais com as quais Laura Janina Hosiasson dialoga ao longo de todo o livro, tais como Ernst Kantorowicz, Benedict Anderson, Étienne Balibar, Eric Hobsbawm, entre outros.

No segundo capítulo, "Heróis sem nome: os Colorados Bolivianos", a autora realiza um estudo sobre a fabricação de heróis nacionais, criaturas que encarnam os

Revista Eletrônica da ANPHLAC, n.14, p. 325-329, jan./jun. 2013. http://revista.anphlac.org.br/index.php/revista 
valores e caracteres positivos de toda pátria. Contudo, a reflexão que ali se realiza segue por um caminho inusitado, pois, ao invés de recorrer a textos nos quais sobejem exaltações a personalidades consagradas, Laura Hosiasson prefere focalizar a literatura de guerra boliviana, na qual prevalece a censura aos grandes ícones militares e políticos, responsabilizando-os pelas graves perdas sofridas pelo país. A análise se centra no livro Los Colorados de Bolivia (Recuerdos de un Subteniente), redigido pelo ex-combatente boliviano Daniel Ballivián. Trata-se das memórias pessoais de um militar escritas em princípios do século $\mathrm{XX}$, mas que narram os acontecimentos relacionados à Batalha de Tacna, transcorrida em maio de 1880, que colocou em campo de combate as tropas de Peru e Bolívia contra as forças do Chile. Nesse livro estudado não existem indivíduos plenamente virtuosos -até mesmo o militar narrador demonstra possuir os seus vícios desabonadores. O heroísmo, no entanto, também está lá. Encontra-se nas coletividades bolivianas, que defendem incondicionalmente os interesses da pátria. As análises da autora demonstram que os ideais nacionalistas se fazem incorporados ao grupo: no povo, no corpo do exército ou nos chamados Colorados, nome do batalhão boliviano que dá título à obra de Ballivián. Apesar das narrativas de guerra da Bolívia desviarem dos cânones, não apresentando "heróis tradicionais" (aqueles que parecem ter uma vida toda predestinada ao virtuosismo), não deixa de existir ali o "herói coletivo", que comporta em seu seio algumas incertezas e inseguranças nas atitudes individuais. Desse modo, o resultado ao qual as análises chegam é bastante interessante por apontar que mesmo em um contexto adverso, de críticas e suspeitas em relação aos grandes expoentes da vida política e militar, ainda assim, as narrativas nacionalistas da Guerra do Pacífico conseguiam encontrar em sua sociedade, derrotada e abatida, os seus ícones, os seus heróis que honram e passam a integrar o imaginário da nação.

O capítulo três, intitulado "Erótica e Estética da batalha", dedica-se ao estudo da guerra enquanto tragédia estetizada e que transforma, dessa maneira, o conflito em um espetáculo digno de admiração e de regozijo nacionalista. Nessa etapa do livro, Laura Hosiasson debruça-se particularmente sobre o interessante conto "El Cabo de Cañón", escrito em 1898 pelo chileno Antonio Bórquez Solar. Mas as reflexões não se restringem unicamente a este texto, pois a autora estabelece importantes diálogos analíticos com outras obras, entre elas romances, contos, ensaios, relatos e trabalhos de cunho histórico. O recurso a este vasto repertório bibliográfico demonstra a familiaridade da autora com a produção ficcional e não ficcional referente à Guerra do

Revista Eletrônica da ANPHLAC, n.14, p. 325-329, jan./jun. 2013. http://revista.anphlac.org.br/index.php/revista 
Pacífico. Passando por temas como a festa, a guerra, a paisagem e o espetáculo, Laura Hosiasson busca demonstrar como as narrativas nacionalistas sobre o conflito constroem um discurso patriótico repleto de representações múltiplas e contraditórias elaboradas a partir da crueza dos combates, mas que visam, em sentido inverso, dotar os textos nacionais de uma beleza laudatória, no firme propósito de, assim, satisfazer à necessidade estética dos discursos nacionalistas. Desse modo, as narrativas transformam, por exemplo, a paisagem amedrontadora do conflito em um cenário empolgante, ou a luta sangrenta em espetáculo fascinante e, consequentemente, a dor e o sofrimento das batalhas se convertem em euforia e grandiloquência nacionalista. Nessa linha, Laura Janina Hosiasson acerca-se da visão do intelectual e ensaísta Octavio Paz, para quem a estética, no Ocidente, estaria associada ao universo militar. Cabe registrar que não deixa de ser ousada a aproximação efetivada entre textos ficcionais e não ficcionais na realização desta análise, que em essência, busca identificar certa padronização recorrente nos discursos nacionalistas de guerra, os quais estetizam a crueza dos combates em nome de uma apologia à pátria.

O divertido capítulo que encerra o livro de Laura Janina Hosiasson recebe o nome "Guano Maldito ou o Valor da Merda", o qual focaliza particularmente a leitura de duas obras do escritor boliviano Joaquín Aguirre Lavayén: o romance Guano Maldito, publicado em 1976, e a peça teatral Guano Maldito. Tragicomedia Latinoamericana en Tres Actos, elaborada dez anos mais tarde a partir do primeiro texto. Por meio de elementos paródicos e cômicos, as narrativas de Aguirre Lavayén constroem uma percepção da Guerra do Pacífico inserida numa perspectiva histórica mais ampla, uma perspectiva que associa toda a história da América Latina à sanha imperialista e à insaciável cobiça capitalista das potências europeias e, posteriormente, norte-americana. A autora realiza um bem sucedido esforço de associação dessa linha discursiva à produção intelectual e cultural revisionista vigente nos círculos da esquerda latino-americana durante a década de 1970. Nessa perspectiva, o sangrento conflito do século XIX seria, sobretudo, resultado da infeliz ação das elites locais europeizadas manipuladas pelos interesses das potências europeias. Laura Hosiasson demonstra como esse discurso se apoia em elementos da teoria marxista, com foco em aspectos da estrutura econômica que estabelecem relações de exploração e conquista. A partir daí a alteridade é estabelecida, não mais entre os países sul-americanos, mas sim diante das potências imperialistas, gerando, por oposição, uma identificação da América Latina

Revista Eletrônica da ANPHLAC, n.14, p. 325-329, jan./jun. 2013. http://revista.anphlac.org.br/index.php/revista 
enquanto coletividade violentada e explorada. Esta constitui, sem dúvida, uma forma distinta de apresentar a nação e de problematizar as identidades a partir da temática da Guerra do Pacífico.

Ao longo desse percurso analítico, Laura Hosiasson trabalha bem com o arcabouço histórico, mas não perde de vista jamais a ênfase na análise discursiva, manejando com grande habilidade os conhecimentos de sua área de especialidade, a literária. Por meio dos quatro capítulos constituintes do livro Nação e Imaginação na Guerra do Pacífico, é possível constatar o esforço de sua autora em identificar alguns dos padrões, dos elementos recorrentes ou mesmo dos lugares comuns inerentes às narrativas nacionalistas. Como a própria obra deixa registrado, "nem todos os mecanismos discursivos foram esgotados neste trabalho" (p. 164). Os recortes temporais, documentais e conceituais se fazem sempre necessários. Ainda assim, a bemsucedida seleção efetivada pela autora proporcionou a análise de textos repletos de ambiguidades no tocante ao problematizar da nação e do nacionalismo, o que garantiu uma reflexão ampla e enriquecedora.

Em 1881, partindo de trabalhos elaborados pelo chileno Diego Barros Arana, Alfredo d'Escragnole Taunay publicou um livro intitulado A Guerra do Pacífico: Chile versus Peru e Bolívia. Desde então foram pouquíssimas as obras dedicadas ao tema do conflito do Pacífico disponibilizadas no Brasil. Desse modo, é extremamente bem-vindo o lançamento do livro de Laura Janina Hosiasson, resultado de mais uma acertada aposta editorial da Edusp -Editora da Universidade de São Paulo-, que continua a envidar esforços no sentido de publicar ensaios relacionados à América Latina. Nação e Imaginação na Guerra do Pacífico representa uma excelente possibilidade de contato do leitor brasileiro com esse importante momento da história e da cultura regionais. Uma possibilidade a mais de aproximar culturalmente povos tão assemelhados e que ainda mantém significativos distanciamentos.

Recebida em: julho de 2012 e aprovada em: outubro de 2012.

Revista Eletrônica da ANPHLAC, n.14, p. 325-329, jan./jun. 2013. http://revista.anphlac.org.br/index.php/revista 